\title{
Conditions required for a law on active voluntary euthanasia: a survey of nurses' opinions in the Australian Capital Territory
}

Betty Kitchener and Anthony F Jorm University of Canberra, Australia

\section{Abstract}

Objectives-To ascertain which conditions nurses believe should be in a law allowing active voluntary euthanasia (AVE).

Design-Survey questionnaire posted to registered nurses (RNs).

Setting-Australian Capital Territory (ACT) at the end of 1996, when active voluntary euthanasia was legal in the Northern Territory.

Survey Sample-A random sample of 2,000 RNs, representing 54 per cent of the $R N$ population in the ACT.

Main Measures-Two methods were used to look at nurses'opinions. The first involved four vignettes which varied in terms of critical characteristics of each patient who was requesting help to die. The respondents were asked if the law should be changed to allow any of these requests. There was also a checklist of conditions, most of which have commonly been included in Australian proposed laws on AVE. The respondents chose those which they believed should apply in a law on AVE.

Results-The response rate was $61 \%$. Support for a change in the law to allow AVE was 38\% for a young man with AIDS, 39\% for an elderly man with early stage Alzheimer's disease, $44 \%$ for a young woman who had become quadriplegic and $71 \%$ for a middle-aged woman with metastases from breast cancer. The conditions most strongly supported in any future AVE law were: "second doctor's opinion", "cooling off period", "unbearable protracted suffering", "patient fully informed about illness and treatment" and "terminally ill". There was only minority support for "not suffering from treatable depression", "administer the fatal dose themselves" and "over a certain age".

Conclusion-Given the lack of support for some conditions included in proposed AVE laws, there needs to be further debate about the conditions required in any future AVE bills.

(Fournal of Medical Ethics 1999;25:25-30)
Keywords: Nurses; opinions; law; active voluntary euthanasia; Australia

\section{Introduction}

In Australia, the laws governing euthanasia are controlled by the states and territories. Active euthanasia is presently illegal, as is assisted suicide, although suicide itself is not illegal. There have been active euthanasia bills tabled in one state (South Australia in 1996) and two territory parliaments (Australian Capital Territory in 1993, 1995 and 1997 and Northern Territory in 1995). ${ }^{1-6}$ However, the only jurisdiction which has legalised AVE is the Northern Territory with its Rights of the Terminally Ill Act 1995. ${ }^{7}$ The conditions of this act are summarised in table 1 . This legislation was passed in May 1995 but was only in force for a brief time from July 1996 to March 1997. Four people legally ended their lives under the Northern Territory law. This law was subsequently overturned by the passage of the Australian federal parliament's Euthanasia Laws Act 1997 (which is commonly known as the "Andrews Bill", after the Member of Parliament who introduced it). This law prevents the Australian Territories (Northern Territory, Australian Capital Territory and Norfolk Island) from legalising AVE, although the states are not affected by this law.

The issue of AVE has been consistently debated within the Australian Capital Territory parliament, with four bills tabled since $1993 .^{2-5}$ In June 1993 an independent member of the Australian Capital Territory parliament introduced The Voluntary and Natural Death Bill 1993 which "empowered a private citizen, in the terminal phase of a terminal illness, to make a reasoned choice concerning the ending of their life and to seek medical assistance to that end". ${ }^{8}$ This bill also stipulated that a capable person should assist in his or her own euthanasia. It also allowed people, when in sound mind, to appoint someone to 
(1) the patient is at least 18 years;

(2) the patient is suffering from an illness that will result in death;

(3) there is no medical measure acceptable to the patient that can be reasonably undertaken in the hope of effecting a cure;

(4) any medical treatment reasonably available to the patient is confined to the relief of pain and/or suffering with the object of allowing the patient to die a comfortable death;

(5) the patient is not suffering from a treatable clinical depression;

(6) the illness is causing the patient severe pain or suffering;

(7) the medical practitioner has informed the patient about the nature of the illness and all forms of treatment;

(8) the patient has considered the implications of his/her decision on family;

(9) the patient is of sound mind;

(10) the patient has made the decision freely, voluntarily and after due consideration;

(11) no earlier than 7 days after requesting AVE, the patient signs the certificate of request;

(12) two other medical practitioners (one a psychiatrist, the other experienced in treating the terminal illness from which the patient suffers) have examined the patient and confirmed the above;

(13) the first medical practitioner witnesses the patient's signature on the certificate of request;

(14) a second medical practitioner signs this certificate in presence of the patient and first doctor;

(15) there will be no financial or other advantage to the doctors involved or to a close relative or associate of either of them, as a resulti of the death of the patient;

(16) no less than 48 hours elapses after the signing of the certificate of request;

(17) the medical practitioner provides the assistance and/or the medical practitioner remains present while the assistance is given and until the death of the patient.

make end-of-life decisions for them by giving that person enduring power of attorney. This bill was referred to the Select Committee on Euthanasia which, in March 1994, withdrew the bill and replaced it with the Medical Treatment Bill 1994, which allowed the withholding or withdrawal of medical treatment, ie passive euthanasia. In all states and territories of Australia there is a common law right for the patient to request the withholding or withdrawal of medical treatment and a common law right of the medical practitioner against medical trespass for meeting this request. This passive euthanasia bill was accepted by the Australian Capital Territory Parliament in September 1994, effectively replacing the common law right with statute law. A similar law already existed in the states of Victoria and South Australia. ${ }^{9}{ }^{10}$ Following the successful Northern Territory legislation, another AVE bill, the Medical Treatment (Amendment) Bill 1995 was introduced in September 1995 into the Australian Capital Territory Parliament. This was defeated in November 1995. A similar Medical Treatment (Amendment) Bill 1997 was tabled in February 1997 , but was withdrawn following the enactment of the Australian federal parliament's Euthanasia Laws Act 1997 in March 1997. The latest attempt was the Crimes (Assisted Suicide) Bill 1997, tabled in September 1997, which tried to circumvent the federal law by introducing a nominal fine for a medical practitioner who assisted in AVE. This bill has since lapsed.

A number of surveys have been carried out in Australia which show a majority of the public, ${ }^{11-14}$ nurse $^{15-17}$ and medical practitioners ${ }^{14}{ }^{18-20}$ support change to the law to allow AVE. In 1995, a survey of 1,158 members of the Australian public found that $78 \%$ supported AVE for a terminally ill patient in great pain. ${ }^{11}$ However, the general pub₹ lic may have limited contact with people request $\overrightarrow{{ }_{0}}$ ing AVE, whereas health practitioners have greatefo experience and perhaps more opportunities ti consider the issues involved. For example, survey of Australian nurses have found that many have received requests for AVE and some have been involved in the provision of AVE. ${ }^{15}{ }^{16}$ Pooling of data from surveys of Australian health practition $\Rightarrow$ ers has shown that $71 \%$ of nurses and $57 \%$ o $\frac{3}{3}$ doctors support change in the law. ${ }^{17}$

It is important to know not only whether healtip practitioners support change in the law to allow AVE, but also what conditions they believe the lavo should specify. The purpose of this paper is to loo at the conditions that nurses in the Australiat? Capital Territory think should be in an AVE law and to compare these conditions to those in the AVE laws which have been proposed in Australia? This study used two methods to investigate thes conditions: a series of vignettes and a checklist of conditions. There appears to be no previous research on health practitioners' views about spet cific conditions in any AVE law although on study has used the vignette method to investigate public opinions towards AVE in Canada. ${ }^{21}$

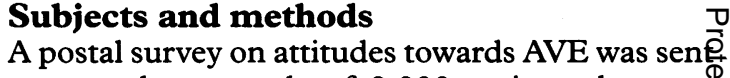
to a random sample of 2,000 registered nurse $\$$ who were currently registered and resident in the Australian Capital Territory, (out of a population of 3,688 registered nurses). ${ }^{22}$ The postal question naire defined active voluntary euthanasia as "the practice of hastening a person's death, througt such means as a lethal injection, which is carriet out with the patient's knowledge and consent. 
Table 2 The four vignettes and percentage of nurses agreeing that the law should be changed to allow AVE in each case

Vignettes

Percent endorsing $(95 \% C I)$

Vignette 1. Martin is a 29-year-old man who was diagnosed with AIDS 12 months ago. He wants help to die now before he loses his independence and self-dignity.

Vignette 2. Ernie is a 78-year-old man recently diagnosed with Alzheimer's disease. He has major memory impairment for recent events. He wanders around home all day repeatedly telling his wife he is tired of living and wants to die. He has asked his doctor to help him die.

Vignette 3. Kirsty is a mentally competent 25 -year-old woman who became a quadriplegic following a swimming accident. She has been living in a nursing home for the last three years and has consistently found her situation intolerable. She has been asking her medical practitioner for help to die.

Vignette 4. Susan is a 45-year-old woman with metastases from breast cancer. She is in pain and becoming more debilitated. She continually states that the palliative nurses and their care are excellent but she still requests to be helped to die peacefully now.

This could be carried out either by a doctor giving an injection or by a patient being provided with the means to commit suicide." The questionnaire began with questions on attitudes to AVE, (including some from earlier Australian surveys of the general public and health practitioners). Questions were also asked to assess nurses' opinions about what conditions should be in a law on AVE. These opinions were assessed by two methods. The first method involved four vignettes which varied in terms of critical characteristics of each patient such as age, medical condition, cognitive competence, terminal illness, disability and quality of life. These vignettes are shown in table 2 . In each vignette, the patient was requesting help to die and the respondent was asked: "Should the law be changed to allow such a person's request to be carried out?" The second method used a checklist of conditions from which the respondent chose those which should apply in a law on AVE. The wording of the question was: "Imagine the law was going to be changed to allow doctors to take active steps to bring about the death of a patient who has requested it. What conditions should the law specify before this is allowed? Tick as many boxes as needed." The conditions listed were broadly based on those in the Northern Territory's Rights of the Terminally Ill Act 1996 and the Australia Capital Territory's Voluntary and Natural Death Bill 1993. The conditions are shown in table 3. Respondents were also asked to "specify any other conditions". At the end of the questionnaire, participants were invited to add any comments on the issue of AVE. Finally, information was collected on the characteristics of the respondents, one of which was on how much interest they took in the public debate about the voluntary euthanasia bill which was introduced into the Australian Capital Territory Legislative Assembly in 1993. A cover letter was sent to explain the reasons and importance of the survey and a postfree envelope enclosed. A reminder/thank you letter was sent to all subjects three weeks after the first posting as an attempt to increase the response rate. Ethical approval was obtained from the University of Canberra's Committee for Ethics in Human Research.

Data were analysed in terms of per cent frequency of responses and $95 \%$ confidence intervals were calculated for the per cent frequencies, using the normal approximation method. ${ }^{23} \mathrm{~A}$ content analysis of themes was carried out on the answers from the open-ended question on any other conditions of the law.

\section{Results}

Table 2 shows the percentage of nurses supporting a change in the law to allow euthanasia for each vignette. It can be seen that there was only minority support for euthanasia in all cases except in case 4 , which involved a middle-aged woman in pain with metastases from breast cancer.

Table 3 shows the percentage of nurses endorsing various conditions that a law on AVE should specify. It can be seen that $20 \%$ selected the option that AVE should not be allowed under any circumstances, despite the instruction to "imagine the law was going to be changed". The table also shows the percentage endorsing each condition when these nurses are excluded. After this exclusion, a majority supported all but three conditions. These were: "only if not suffering from treatable depression", "only if the patient administers, or assists to administer, the fatal dose" and "only if patient is over a certain age". A modal age of 18 years was given by those endorsing an age limit.

Because some nurses may not have a wellthought-out position on a law for euthanasia, a percent frequency analysis was also carried out on just the responses of the $47 \%$ of nurses who reported taking a lot of interest in the public debate about voluntary euthanasia. The results showed that, while there was a somewhat larger percentage of nurses who stated that a law allowing euthanasia should not be allowed under any circumstances $(26 \%$ versus $20 \%)$, and a 
28 Conditions required for a law on active voluntary euthanasia: a survey of nurses' opinions in the Australian Capital Territory

Table 3 Nurses'opinions about the conditions a euthanasia law should specify : \% endorsing (and 95\% CI)



Conditions (in descending order of endorsement)

Only if a second doctor confirms that all requirements of the euthanasia law have been met.

Only if there is a cooling-off period after a patient makes a formal request for euthanasia.

Only if patient has an irreversible condition causing protracted physical or mental suffering which the patient finds unbearable.

Only if the doctor has informed the patient about the nature of the illness and all forms of treatment.

Only if terminally ill.

Only if a doctor is present while euthanasia is carried out.

Only if palliative care has been tried.

Only if cognitively competent.

Only if palliative care options are given.

Only if request is witnessed by two non-relatives.

Only if the patient is in intractable pain.

Only if not suffering from treatable depression.

Only if patients administer, or assist to administer, the fatal dose themselves.

Should not be allowed under any circumstances.

Only if the patient is over a certain age.

\begin{tabular}{ll}
$\begin{array}{l}\% \text { endorsing } \\
\text { (all nurses) }\end{array}$ & $\begin{array}{l}\% \text { endorsing (excluc } \\
\text { totally opposed to }\end{array}$ \\
\hline $69 \%(66-72)$ & $85 \%(83-87)$ \\
$66 \%(63-68)$ & $81 \%(78-83)$ \\
& \\
$65 \%(63-68)$ & $80 \%(78-83)$ \\
& \\
$63 \%(61-66)$ & $78 \%(76-81)$ \\
$52 \%(49-55)$ & $63 \%(60-66)$ \\
$46 \%(43-48)$ & $56 \%(53-59)$ \\
$45 \%(42-48)$ & $56 \%(52-59)$ \\
$44 \%(42-47)$ & $54 \%(51-57)$ \\
$44 \%(41-47)$ & $54 \%(51-57)$ \\
$44 \%(41-47)$ & $54 \%(51-58)$ \\
$42 \%(40-45)$ & $52 \%(49-55)$ \\
$34 \%(32-37)$ & $42 \%(39-45)$ \\
$27 \%(24-29)$ & $32 \%(29-35)$ \\
$20 \%(17-22)$ & Not applicable \\
$6 \%(5-7)$ & $7 \%(6-9)$
\end{tabular}

"only if the patient administers, or assists tक्ष administer, the fatal dose" and "only if patient is over a certain age". Furthermore, only around half the nurses supported the conditions that: pal liative care options must be given or tried; that the patient is cognitively competent; that the doctor must be present during euthanasia; that the request must be witnessed by two non-relatives and, that the patient must be in intractable pain. $\frac{\bigcirc}{\mathbb{Q}}$

It is interesting that only $42 \%$ thought that the patient should not be suffering from treatable depression. Although the Northern Territory's Rights of the Terminally Ill Act 1995, the Soutt Australian Voluntary Euthanasia Bill 1996, and the Western Australian Voluntary Euthanasia Bill 199 required that the patient "is not suffering from treatable clinical depression", the Australiat Capital Territory's AVE bills have not required this condition. A difficulty with this condition is that many terminally ill patients may have justifi? able depressive symptoms with respect to their illo ness. Physical illness is a major risk factor for depression and it is difficult to treat where physion cal illness is present. ${ }^{24}$

Only a third of nurses supported the require+్టి ment that patients had to administer the fatal dose themselves. In other words there is not widespreat support for physician-assisted suicide as the onl method for AVE. Consistent with this, surveys of Australian medical practitioners and nurses have found lower support for physician-assisted suicide than for homicide by request (where the letha: dose is administered by the medica $\mathbb{B}$ practitioner). ${ }^{17}$ This preference for homicide b request is contrary to ethical arguments thag physician-assisted suicide is morally preferable because it allows a patient to retain greate 5 . autonomy. ${ }^{25}$ Autonomy is generally acknowledgec. as one of the basic ethical principles in patient 
care ${ }^{26}$ Consistent with this principle of autonomy, the Australian Capital Territory's Voluntary and Natural Death Bill 1993 required that a person capable of doing so, should assist in his or her own death. It may be that nurses did not support this requirement because they are aware that it may be physically impossible for some patients to administer the dose themselves, for example a patient with cervical level quadriplegia.

The least supported condition (7\%) was an age restriction on the person requesting AVE. By contrast, all the bills introduced into the Australian parliaments have stipulated the patient "has attained the age of 18 years". With respect to age, the nurses might be seen as supporting euthanasia for patients under the age of 18 years. However, some nurses may have read the question as only relating to adults, leaving this issue of age unclear.

All the Australian bills have included a requirement that the patient be "of sound mind". By contrast, there was divided opinion in the checklist about whether the patient needed to be cognitively competent. Opinions about the man with Alzheimer's disease in vignette 2 may also reflect the dilemma of cognitive competency. The divided opinion among nurses may be because they know that cognitive incompetency can occur during the dying process due to organic brain dysfunction. ${ }^{27}$ In the comments written on the questionnaire, some nurses advocated that provision be made for legal advance directives in the form of living wills or enduring power of attorney, which would allow for medical treatment when a person becomes cognitively incompetent. While the Northern Territory act did not allow for advance directives, the Australian Capital Territory 1993 bill and the South Australian bill 1996 did allow for this.

\section{Palliative care options}

There were divided views over whether palliative care options needed to be given or tried. All the Australian AVE bills stated that information on palliative care options must be given, but some also required that these options be tried where there is a likelihood of benefit to the patient..$^{3-6}$ Related to this issue, there is a strong agreement from the Australian public (75\%), medical practitioners $(79 \%)$ and nurses $(81 \%)$ that good palliative care will not prevent all requests for euthanasia. ${ }^{17}$

Another condition about which there were divided views was that the patient had to have intractable pain. However, this result needs to be taken together with the overwhelming support for the condition that the "patient had to have an irreversible condition causing protracted physical or mental suffering which the patient finds unbearable". The nurses are supporting suffering in a broader sense, rather than pain specifically. All Australian AVE bills have adopted this broader concept except for one bill which did not specify either. $^{2}$

While nearly two-thirds of nurses thought that terminal illness should be a requirement, support was not as strong as for some other conditions. This is an interesting result in view of the fact that all Australian AVE bills have required terminal illness (except the South Australian bill). The latter bill proposed a situation as in The Netherlands where the patient is eligible for AVE if he or she has an irreversible condition causing protracted physical or mental suffering which the patient finds unbearable, but need not be terminally ill. Nurses do not appear to be supporting these more liberal conditions.

\section{Counselling}

The most common suggestions nurses gave for conditions apart from those listed in the checklist were: advance directives be legal; counselling be provided for the patient, and counselling and involvement be provided for the relatives. None of the Australian bills have had provisions requiring counselling. Because these conditions were not included in the checklist, the degree of support for them is unknown.

In considering the present results, the limitations of the present study need to be borne in mind. A limitation of the checklist method is that it looks at each condition in isolation, devoid of context. The vignettes attempted to overcome this limitation, although some nurses did comment that more information was still needed about the patient's life situation. The major limitation of the vignettes is that it is hard to attribute which features of the case are influencing respondents' opinions. However, the two methods do show concordance with each other in that the vignette that received the most support (the woman with metastases from breast cancer), is also the one that encompasses more of the conditions in the checklist which were given majority support.

In conclusion, there is widespread support among nurses for some, but not all, of the conditions in Australian AVE bills. Thus, there needs to be further debate among the public, health practitioners and legislators about which conditions should be required in any future AVE bills. Although the public have been clearly in favour of changing the law, ${ }^{11-14}$ the members of the lower and upper houses of the Australian federal parliament have not. To what extent should parliamentarians reflect the will of the people? If it is the 
duty of elected representatives to reflect the views of their constituents, it would appear they have shown themselves remiss in this duty. However, if they are sages who are elected to lead the community, they may be satisfied that they are doing their duty towards their constituents. If the parliamentarians are to be wise, they need to be appropriately informed and surveys of health practitioners, who have been confronted by the dilemmas of euthanasia in their daily work, can help to provide this information.

\section{Acknowledgement}

Thanks to David Jorm for assistance with a statistical programme for this paper and to the Judy Gallagher Memorial Trust for help with funding of the survey.

Betty A Kitchener BA, BNurs, Grad Dip Spec Ed, Grad Dip Comm Couns, is a Postgraduate Student in the School of Nursing, University of Canberra, Australia and Anthony F form PhD, DSc, is Professor in the NHMRC Psychiatric Epidemiology Research Centre, Australian National University, Canberra, Australia.

\section{References}

1 Legislative Assembly of South Australia. Voluntary Euthanasia Bill 1996.

2 Legislative Assembly for the Australian Capital Territory. Voluntary and Natural Death Bill 1993.

3 Legislative Assembly for the Australian Capital Territory. Medical Treatment (Amendment) Bill 1995.

4 Legislative Assembly for the Australian Capital Territory. Medical Treatment (Amendment) Bill 1997.

5 Legislative Assembly for the Australian Capital Territory. Crimes (Assisted Suicide) Bill 1997.

6 Legislative Assembly of the Northern Territory. Rights of the Terminally Ill Bill 1995.

7 Kerridge IH, Mitchell KR. The legislation of active voluntary euthanasia in Australia: will the slippery slope prove fatal? fournal of Medical Ethics 1996;22:273-8.
8 Legislative Assembly for the Australian Capital Territory. Sele Committee on Euthanasia report: Voluntary and Natural Death Bivith 1993. 1994.

9 Legislative Assembly of Victoria. Medical Treatment Act 1988.읃

10 Legislative Assembly of South Australia. Consent to Medic Treatment and Palliative Care Act 1995.

11 Roy Morgan Research Centre. Finding No 2768: Support fिक्ठ euthanasia strong and steady. Melbourne: Roy Morgan Research Centre, 1995 Jul 4.

12 Grattan M. General support for right to die: survey. Canberra Times 1995 Feb 6: 2.

13 Dow S. Overwhelming support for pro-euthanasia law reform:Newspoll. Weekend Australian 1994 Jul 30: 1-2.

14 Steinberg MA, Najman JM, Cartwright CM, MacDonald, SN Williams GM. End-of-life decision-making: community ant medical practitioners' perspectives. Medical fournal of Australi 1997;166:131-5.

15 Kuhse H, Singer P. Voluntary euthanasia and the nurse: aor Australian survey. International fournal of Nursing Studies 1993; 30:311-22.

16 Stevens CA, Hassan R. Nurses and the management of death? dying and euthanasia. Medicine and Law 1994;13:541-54.

17 Kitchener B. Nurses' attitudes to active voluntary euthanasia: survey in the Australian Capital Territory. Australian $\mathcal{E} N e \vec{w}$ Zealand fournal of Public Health 1998;22:276-8.

18 Kuhse H, Singer P. Doctors' practices and attitudes regardin voluntary euthanasia. Medical fournal of Australia 1988;148623-7.

19 Stevens CA, Hassan R. Management of death, dying and euthanasia: attitudes and practices of medical practitioners i $\vec{B}$ South Australia. Fournal of Medical Ethics 1994;20:41-6.

20 Baume P, O'Malley E. Euthanasia: attitudes and practices of medical practitioners. Medical fournal of Australia 1994;16ł 137-44.

21 Genuis SJ, Genuis SL, Chang W-C. Public attitudes toward the right to die. Canadian Medical Association Fournal 1994;150? 701-8.

22 Nurses Board of the Australian Capital Territory. Nurses regis tered and enrolled in the ACT under the Nurses Act 1988. Specig Gazette No S134. ACT: Nurses Board of the Australian Capital Territory, 1996 Jun 28.

23 Armitage P, Berry G. Statistical methods in medical research Oxford: Blackwell Scientific Publications, 1987.

24 Jorm AF. The epidemiology of depressive states in the elderly implications for recognition, intervention and prevention. Social Psychiatry and Psychiatric Epidemiology 1995;30:53-9.

25 Watts DT, Howell T. Assisted suicide is not voluntary activ euthanasia. Fournal of the American Geriatrics Society 1992;40. 1043-6.

26 Coyle N. The euthanasia and physician-assisted suicide debate. issues for nursing. Oncology Nursing Forum 1992;19:41-6.

27 Bruera E, Miller L, McCallion J. Cognitive failure in patients with terminal cancer: a prospective study. Fournal of Pain and Symptom Management 1992;7:192-5.

\section{News and notes}

\section{Mental Disorders and Genetics: the Ethical Context}

Special safeguards must be implemented to protect people with mental disorders from genetic testing that would not be beneficial to those people, says the Nuffield Council on Bioethics. In the council's report, Mental Disorders and Genetics: the Ethical Context, the ethical implications arising from genetic research and how the research is applied are reviewed on the basis of the fundamental need to preserve human respect and human dignity.

The report is available from the Nuffield Council on Bioethics, 28 Bedford Square, London WC1B 3EG, price $£ 20.00$ inc p\&p within Europe $(+£ 3.50$ per copy outside Europe). 